\title{
The Appeals Process in Principal-Agent Relationships
}

\author{
Chifeng Dai* \\ Department of Economics \\ University of Florida \\ 224 Matherly Hall \\ P.O. Box 117140 \\ Gainesville, FL 32611 \\ chifeng.dai@cba.ufl.edu
}

*I am grateful to David Sappington for his guidance and suggestions. I thank a co-editor, two referees, David Denslow, Jonathan Hamilton, Tracy Lewis, and Steven Slutsky for their comments. Financial support from a Walter-Lanzillotti research grant is gratefully acknowledged. 


\begin{abstract}
The appeals process is employed in many organizations, including administrative agencies, regulatory authorities, sports organizations, and private companies. This paper examines the dual role of the appeals process in correcting errors and inducing compliance in principal-agent relationships in the presence of imperfect performance evaluation. Some surprising results emerge. For example, appeals may be denied even if the appeals process is quite accurate and costless. An increased accuracy of initial observation may reduce welfare. Furthermore, welfare can increase as the cost of the appeals process increases.
\end{abstract}




\section{Introduction}

Social scientists (e.g., Aram and Salipante, 1981; Okun, 1975) have long considered justice (fairness) as a basic requirement for the effective functioning of organizations. A fundamental principle of organizational justice is correctness (Sheppard, Lewicki, and Minton, 1992). The objective of this paper is to examine the dual role of the appeals process in enhancing justice and securing compliance in principal-agent relationships in the presence of imperfect performance evaluation. Justice is measured as the correctness of the performance evaluation.

I consider a simple principal-agent relationship where a risk-neutral employer induces a risk-neutral employee to achieve a certain level of performance under limited liability. The employer requires at least a minimum performance from all employees, but prefers to induce a superior (and more costly) performance from a high-productivity employee. The employer cannot observe the employee's productivity, and can only measure his performance imperfectly. Consequently, incorrect performance evaluations may arise. In contrast, the employee is privately informed about his own productivity and his effort at work, and can observe his performance perfectly. The employer's welfare depends on both her profit and the perceived justice within her organization. I examine the effect of an appeals process where the employee is allowed to lodge an appeal when he is initially found shirking. Four primary observations emerge from the analysis.

First, the merit of the appeal process largely depends on the employer's concern for justice (i.e., correctness). In a standard principal-agent model, the employer's optimal strategy would be to audit an employee’s performance when he claims to have high productivity and is initially found to have delivered superior performance. The employee 
is rewarded only if the audit also reveals superior performance. Doing so maximizes the possibility of penalizing a shirking employee and minimizes the cost of securing compliance. However, this auditing strategy increases evaluation errors when the audit is imperfect. The reason is that in equilibrium a high-productivity employee always delivers superior performance. Therefore, the audit is triggered by-and may mistakenly reversecorrect initial evaluations. In contrast, the appeals process allows an employee to appeal when he is initially found shirking (an event that in equilibrium occurs only as a result of evaluation errors). Hence, the appeals process is triggered by-and can reverse-incorrect initial evaluations. When the employer cares enough about the correctness of the performance evaluation, the appeals process becomes the optimal strategy.

Second, the employee may initially be paid more for minimum performance than for superior performance. The reason is that, when the appeals process is sufficiently accurate, the employer delivers the greatest reward only to an employee who is found in the appeals process to have delivered superior performance. Doing so best limits the rent the employee derives from evaluation errors. However, the employer may deliver a positive payment when the employee is found to have delivered minimum performance in the initial stage to prevent one who has truly delivered minimum performance from appealing.

Third, surprisingly, more accurate initial evaluations may reduce the employer's welfare. This is because increased accuracy of the initial evaluation provides more opportunities for dishonest employees to appeal than for honest employees. Consequently, more accurate initial evaluations may restrict the employer's ability to reward different performance levels differentially through the appeals process. 
Fourth, the appellant bears all the costs of the appeals process and the employer's welfare can increase as the cost of appeals increases. The cost of appealing can act as a forfeitable bond an employee must post in order to appeal, which helps deter a shirking employee from appealing. As a result, the employer's welfare can increase as the cost of the appeals process increases when she can impose a large share of the cost of the appeals process on the appellant.

Shavell (1995) studies the role of the appeals process as a means of error correction in judicial settings where either parties disappointed with the decision of a first-order tribunal can seek reconsideration before a higher tribunal. In contrast, I study the role of the appeals process in both reducing evaluation errors and securing compliance in a principal-agent setting where an agent can seek the principal's reconsideration of her initial decision. Daughety and Reinganum (2000) examine judicial decision making in a hierarchical judicial system. In their model, the role of an appeals court is to use the defendant's choice about appeal to improve its estimate of the superior court's preferred interpretation of the law. In my model, both the initial evaluation and the appeals process serve to measure an employee's performance. Spitzer and Talley (2000) analyze a hierarchical system of judicial auditing where an appeals court is concerned with imprecision and ideological bias of a trial court. In contrast, there is no difference in ideology between the initial evaluation and the appeals process in my model. Polinsky and Shavell (2000) incorporate the notion of fairness of sanction into a standard model of enforcement and show that the concern for fairness not only affects the magnitude of sanctions but also influences the optimal probability of enforcement. The 
main concern for fairness in this paper is the correctness of evaluation instead of the magnitude of punishment.

Cremer (1995) shows that better information about the performance of an agent may make it more difficult for the principal to commit to threats and weaken the agent's incentive. In this paper, increased accuracy of the initial evaluation weakens incentives because it restricts an industrious employee's access to the appeals process (a favorable lottery) more than it does to a shirking employee.

Section 2 describes the central elements of the model. Section 3 presents the optimal contract without an appeals process as a benchmark. Section 4 examines the effect of the appeals process. Section 5 discusses the employer's preference between the appeals process and auditing. Section 6 concludes the paper with future research directions. The proofs of all formal conclusions are in the Appendix.

\section{The model}

A risk-neutral employer induces a risk-neutral employee to achieve a certain level of performance Q. $e(\alpha, Q)$ denotes the level of effort required to achieve performance $\mathrm{Q}$ when the employee's productivity is $\alpha$. More effort is required to produce higher quality, regardless of the employee's productivity, so $e_{Q}(\alpha, Q)>0$. More effort is also required to achieve a specified level of performance the lower is the employee's producitivty, so $e_{\alpha}(\alpha, Q)<0$. The employee's productivity $\alpha$ is the realization of a binary random variable. High productivity, $\alpha_{H}$, is realized with probability $\mu_{H}$, while low productivity, $\alpha_{L}$, is realized with probability $\mu_{L}$, where $0<\alpha_{L}<\alpha_{H}$ and $\mu_{H}+\mu_{L}=1$. The employee is privately informed about his productivity $\alpha$ and effort $e$. The 
employee's marginal cost of effort is assumed to be constant and is normalized to unity, regardless of his productivity. The employee's opportunity wage is zero.

There is an exogenous, minimum performance level $Q_{L}$ that the employer requires of all employees. The employer prefers an exogenous higher performance level $Q_{H}$ from the high-productivity employees, but not the low-productivity employees, because the extra benefit the employer derives from the increased performance exceeds the incremental cost of the superior performance for the high-productivity employees but not for the low-productivity employees. ${ }^{1}$ Minimum performance could be basic duties such as arriving at work on time and doing routine assignments, but superior performance might entail outstanding creativity or efficiency. The employer cannot evaluate the superior performance perfectly, but can observe perfectly (and therefore deter) any performance below the minimum performance. Conditional on the employee's actual performance being $Q_{H}$, the evaluation outcome is $Q_{H}$ with probability $p_{H}>\frac{1}{2}$ and $Q_{L}$ with probability $1-p_{H}$; conditional on the employee's performance being $Q_{L}$, the evaluation outcome is $Q_{H}$ with probability $p_{L}<\frac{1}{2}$ and $Q_{L}$ with probability $1-p_{L} . J$ denotes the loss of justice due to an evaluation error.

The employer pays the employee with a transfer payment $\mathrm{T}$ which can vary with the employee's announcement of his productivity and the employer's evaluation. Institutional or legal restrictions impose a lower bound on the employee's compensation. For simplicity, we assume the all payment must be nonnegative. The employee's utility function is $U=T-e$ which is the payment he receives, $T$, minus the cost of his effort, $e$. The employer's welfare function is $W(Q, T)=V(Q)-T-J$ which is her profit from 
performance $Q$ minus the payment she delivers and any loss of justice due to evaluation errors.

The timing of the model is as follows: (1) The employee observes his productivity $\alpha$. (2) The employer offers a contract specifying the payment $\mathrm{T}$ as a function of the employee's announcement of his productivity and the evaluation outcome. (3) The employee announces his productivity. (4) The employee chooses effort e and delivers performance. (5) The employer evaluates the employee’s performance. (6) The employee is paid based upon the evaluation outcome and his ex ante announcement. I abstract from the appeals process until section 4 .

\section{The optimal contract without an appeals process}

\subsection{The optimal contract with perfect evaluation}

Let $T_{H}$ and $T_{L}$ denote the payments the employer delivers to the employee when the evaluation of his performance are $Q_{H}$ and $Q_{L}$, respectively. When the employer can evaluate the employee's performance perfectly, the optimal payment structure is characterized by the following equations as in standard principal-agent models:

$$
\begin{aligned}
& T_{L}=e\left(\alpha_{L}, Q_{L}\right) ; \text { and } \\
& T_{H}=\Delta e+e\left(\alpha_{L}, Q_{L}\right)
\end{aligned}
$$

where $\Delta e=e\left(\alpha_{H}, Q_{H}\right)-e\left(\alpha_{H}, Q_{L}\right)$. Equation (3.1) indicates that the lowproductivity employee receives no rent. Equation (3.2) implies that the high-productivity employee receives positive rent because of his private information about his superior productivity. I will call the optimal outcome (contract) in this setting the second-best outcome (contract). 


\subsection{The optimal contract with imperfect evaluation}

Now consider the optimal contract when the employer cannot evaluate the employee's performance perfectly. Before formally modeling the employer's problem, I present an observation regarding the optimal mechanism.

Observation 1: The employer evaluates the employee’s performance only when he claims to be a high-productivity employee.

The intuition behind Observation 1 is the following. When the employee claims to be low-productivity, he is required to deliver minimum performance. He has no incentive to deliver superior performance, as higher performance demands higher effort. Therefore, evaluating the employee's performance when he claims to be a low-productivity employee is unnecessary.

Let $T_{H}^{H}$ and $T_{L}^{H}$ denote the payments for an employee who claims to be a highproductivity employee when he is found to have delivered superior and minimum performance, respectively. Let $T^{L}$ denote the payment for an employee who claims to be a low-productivity employee. Then the employer's problem, labeled [P-NA], is

$$
\underset{T_{H}^{H}, T_{L}^{H}, T^{L}}{\operatorname{Max} W}=\mu_{H}\left\{V\left(Q_{H}\right)-p_{H} T_{H}^{H}-\left(1-p_{H}\right)\left(T_{L}^{H}+J\right)\right\}+\mu_{L}\left\{V\left(Q_{L}\right)-T^{L}\right\}
$$

subject to the standard participation conditions and incentive compatibility conditions that guarantee the employee's participation and compliance regardless of his productivity $^{2}$. In addition, all payments must be non-negative due to the limited liability.

The properties of the optimal contract in [P-NA] are presented in Observation 2.

Observation 2: The solution to [P-NA] has the following features:

(i) The loss of justice due to evaluation errors is $\mu_{H}\left(1-p_{H}\right) J$; 
(ii) When $\frac{p_{H}}{p_{L}} \geq 1+\frac{\Delta e}{e\left(\alpha_{L}, Q_{L}\right)}$, limits on liability and imperfect performance evaluation do not affect the employer's expected payment;

(iii) When $\frac{p_{H}}{p_{L}}<1+\frac{\Delta e}{e\left(\alpha_{L}, Q_{L}\right)}$, the employee receives $\frac{\Delta e}{p_{H}-p_{L}}$ when evaluation reveals superior performance, and zero when the evaluation reveals minimum performance. The employee receives positive expected rent regardless of his productivity;

(iv) An employee who admits to be low-productivity receives a fixed and positive payment for his performance.

To understand Observation 2, it is important to understand how the imperfect evaluation affects the employee's behavior. When the performance evaluation is imperfect, a high-productivity employee may exaggerate his performance when he actually delivers only minimum performance, and a low-productivity employee may exaggerate both his productivity and performance.

When the evaluation is relatively accurate $\left(\frac{p_{H}}{p_{L}}\right.$ is large), evaluation errors are relatively rare. When the incremental effort the high-productivity employee must exert to achieve the superior performance $\Delta e$ is small, the employee's benefit from shirking is small. Furthermore, when the low-productivity employee must exert substantial effort to achieve minimum performance (i.e., when $e\left(\alpha_{L}, Q_{L}\right)$ is large), he receives a large payment for his participation and his benefit from pretending to be a high-productivity employee is relatively small. Hence, if $\frac{p_{H}}{p_{L}} \geq 1+\frac{\Delta e}{e\left(\alpha_{L}, Q_{L}\right)}$, the employer can ensure the 
employee truthfully announces his productivity and delivers appropriate performance by imposing a relatively small penalty when the evaluation reveals minimum performance. Consequently, limits on liability do not reduce the employer's expected welfare.

In contrast, when $\frac{p_{H}}{p_{L}}<1+\frac{\Delta e}{e\left(\alpha_{L}, Q_{L}\right)}$, the employer would have to either impose a large penalty when the evaluation reveals minimum performance or raise her payments in other occasions in order to induce the employee's compliance. When large penalties are not feasible, the employer has to deliver a larger expected payment than in the second-best contract. Consequently, the employee receives positive rent regardless of his productivity.

To best demonstrate the effect of the appeal process, the rest of the paper focuses on situations where the limits on liability are constraining. In other words, Assumption 1 is made for the rest of the paper.

$$
\text { Assumption 1: } \frac{p_{H}}{p_{L}}<1+\frac{\Delta e}{e\left(\alpha_{L}, Q_{L}\right)} \text {. }
$$

\section{The appeals process}

This section examines an appeals process which allows the employee to lodge an appeal when he is found shirking. Upon the employee's appeal, the employer launches an investigation about the employee's performance at certain cost. Call this setting "the appeals setting." Conditional on the employee's performance being $Q_{H}$, the investigation outcome is $Q_{H}$ with probability $a_{H} p_{H}$ and $Q_{L}$ with probability $1-a_{H} p_{H}$; conditional on the employee's performance being $Q_{L}$, the investigation outcome is $Q_{H}$ with 
probability $a_{L} p_{L}$ and $Q_{L}$ with probability $1-a_{L} p_{L} \cdot a_{H}$ and $a_{L}$ measure the difference between the accuracy of the appeals process and that of the initial evaluation. The appeals process normally has access to the same information that the initial evaluation had plus additional information. Therefore, I assume $a_{H}>1$ and $a_{L}<1$, i.e., the appeals process is more accurate than the initial evaluation. Let $C$ denote the total cost of the appeals process which includes the relevant cost of both the employer and the appellant. Let $T_{H}^{A}$ and $T_{L}^{A}$ denote the payments for superior performance and minimum performance in the appeals process, respectively. Denote the share of the cost of the appeals process borne by the employer as $r$. The sequence of actions of the employer and the employee in this setting is summarized in Figure 1.

[Figure 1. Sequence of actions]

Before proceeding, I present an observation regarding the appeals process.

Observation 3: In the optimal appeals process, an employee who has delivered minimum performance never appeals. ${ }^{3}$

Suppose an employee who has delivered minimum performance appeals when the initial evaluation reveals minimum performance. The expected payoff the employee receives in the appeals process is $\left(1-a_{L} p_{L}\right) T_{L}^{A}+a_{L} p_{L} T_{H}^{A}-(1-r) C$. Rather than admitting an appeal, the employer will prefer to pay the employee $\left(1-a_{L} p_{L}\right) T_{L}^{A}+a_{L} p_{L} T_{H}^{A}-(1-r) C$ in the initial stage when he is found to have delivered minimum performance. Doing so does not alter either the expected payment received by the employee nor his incentive to deliver performance, but avoids the cost of the appeals 
process that would be incurred if the low-productivity employee appeals. Therefore, an employee who has delivered minimum performance never appeals in the optimal appeals process.

Given Observation 3, the employer's problem in the appeals setting, labeled [PA], can be modeled as follows:

$$
\begin{aligned}
\operatorname{Max} W= & \mu_{H}\left\{V\left(Q_{H}\right)-p_{H} T_{H}^{H}-\left(1-p_{H}\right)\left[a_{H} p_{H} T_{H}^{A}+\left(1-a_{H} p_{H}\right)\left(T_{L}^{A}+J\right)+r C\right]\right\} \\
& +\mu_{L}\left\{V\left(Q_{L}\right)-T^{L}\right\}
\end{aligned}
$$

subject to

$$
\begin{array}{lrl}
U_{H} \equiv p_{H} T_{H}^{H}+\left(1-p_{H}\right)\left[a_{H} p_{H} T_{H}^{A}+\left(1-a_{H} p_{H}\right) T_{L}^{A}-(1-r) C\right]-e\left(\alpha_{H}, Q_{H}\right) \geq 0 ; & \text { IRH } \\
U_{L} \equiv T^{L}-e\left(\alpha_{L}, Q_{L}\right) \geq 0 ; & \text { IRL } \\
U_{H} \geq p_{L} T_{H}^{H}+\left(1-p_{L}\right) T_{L}^{H}-e\left(\alpha_{H}, Q_{L}\right) ; & \text { ICH1 } \\
U_{L} \geq T^{L}-e\left(\alpha_{L}, Q_{H}\right) ; & \text { ICL1 } \\
U_{H} \geq T^{L}-e\left(\alpha_{H}, Q_{H}\right) ; & \text { ICH2 } \\
U_{L} \geq p_{L} T_{H}^{H}+\left(1-p_{L}\right) T_{L}^{H}-e\left(\alpha_{L}, Q_{L}\right) ; & \text { ICL2 } \\
U_{H} \geq T^{L}-e\left(\alpha_{H}, Q_{L}\right) ; & \text { ICH3 } \\
U_{L} \geq p_{H} T_{H}^{H}+\left(1-p_{H}\right)\left[a_{H} p_{H} T_{H}^{A}+\left(1-a_{H} p_{H}\right) T_{L}^{A}-(1-r) C\right]-e\left(\alpha_{L}, Q_{H}\right) ; & \text { ICL3 } \\
T_{L}^{H} \geq\left(1-a_{L} p_{L}\right) T_{L}^{A}+a_{L} p_{L} T_{H}^{A}-(1-r) C ; & \text { ICA } \\
T_{H}^{H} \geq 0 ; & \text { LLHH } \\
T_{L}^{H} \geq 0 ; & \text { LLHL } \\
T^{L} \geq 0 ; & \text { LLL } \\
T_{H}^{A} \geq 0 ; \text { and } & \text { LLAH }
\end{array}
$$


$T_{L}^{A} \geq 0$

LLAL

With probability $\mu_{H}$, the employee has high productivity and achieves superior performance. Initially, the employer finds the employee has delivered superior performance and pays him $T_{H}^{H}$ with probability $p_{H}$, and finds he has delivered minimum performance and pays him $T_{L}^{H}$ with probability $1-p_{H}$. When the highproductivity employee is found to have delivered minimum performance, he rejects payment $T_{L}^{H}$ and lodges an appeal at a cost of $(1-r) C$. In the appeals process, the employer investigates the employee's performance. The investigation entails a total cost of $C$. With probability $a_{H} p_{H}$, the employer finds the high-productivity employee's performance superior in the investigation and delivers payment $T_{H}^{A}$; with probability $1-a_{H} p_{H}$, she mistakenly finds the high-productivity employee has delivered minimum performance and pays him $T_{L}^{A}$ and suffers a loss of $J$ due to the evaluation error. With probability $\mu_{L}$, the employee has low-productivity and delivers minimum performance. Then the employer delivers payment $T^{L}$. Constraints IRH and IRL are the individual rationality constraints, which ensure the participation of the employee regardless of his productivity. Constraints ICH1-3 and ICL1-3 are the incentive compatibility constraints, which ensure the employee truthfully announces his productivity and delivers the desired performance. Constraint ICA guarantees a dishonest employee does not appeal. Constraints LLHH, LLHL, LLL, LLAH and LLAL ensure the payments are nonnegative in both the initial stage and the appeals process.

Denote the maximum welfare the employer can realize in [P-A] and [P-NA] as $\bar{W}^{A}$ and $\bar{W}$, respectively. The employer's problem is to maximize $\left\{\bar{W}^{A}, \bar{W}\right\}$. 
4.1. A costless appeals process.

As a benchmark, I first consider an appeals process involving no cost (i.e., $C=0$ ). In this case, the merits of admitting appeals depend solely on how much the addition of the appeal process improves the evaluation accuracy. The properties of the appeals process depend on the accuracy of the appeals process relative to the accuracy of the initial evaluation, as Proposition 1 reveals.

Proposition 1. When the appeals process is costless, the solution to [P-A] has the following features:

(i) When the employee's concern for justice is minimal, she denies any appeals if $\frac{a_{H}}{a_{L}}<\frac{1-p_{L}}{1-p_{H}} ;^{4}$

(ii) An employee claiming high-productivity initially receives no payment when the evaluation reveals superior performance, but a positive payment when it reveals minimum performance;

(iii) Increased accuracy of the initial evaluation can reduce the employer's welfare;

(iv) When the appeals process is sufficiently accurate, the employer in expectation delivers the second-best payment.

To understand the conclusions drawn in Proposition 1, consider a situation where the limited liability constraints bind. Without the appeals process, the employee receives $T_{H}^{H}$ with probability $p_{H}$ when he delivers superior performance, and with probability $p_{L}$ when he shirks. When the employee is allowed to appeal, the employee receives $T_{H}^{A}$ with probability $\left[1-p_{H}\right] a_{H} p_{H}$ when he delivers superior performance, and with 
probability $\left[1-p_{L}\right] a_{L} p_{L}$ when he shirks. When $\frac{\left(1-p_{H}\right) a_{H} p_{H}}{\left(1-p_{L}\right) a_{L} p_{L}}<\frac{p_{H}}{p_{L}}$, i.e., the appeals process is not sufficiently more accurate than the initial evaluation, implementing the appeals process actually increases the likelihood of rewarding a dishonest employee. Nonetheless, implementing the appeals process reduced the expect loss of justice due to evaluation errors from $\mu_{H}\left(1-p_{H}\right) J$ to $\mu_{H}\left(1-p_{H}\right)\left(1-a_{H} p_{H}\right) J$. Consequently, when $\frac{a_{H}}{a_{L}}<\frac{1-p_{L}}{1-p_{H}}$, the employer implements an appeals process only if she is concerned about justice.

When $\frac{a_{H}}{a_{L}}>\frac{1-p_{L}}{1-p_{H}}$, implementing the appeals process increases the likelihood of rewarding an employee who has delivered superior performance and reduces the employer's expected payment by $\left[\frac{1}{\frac{p_{H}}{p_{L}}-1}-\frac{1}{\frac{\left(1-p_{H}\right) a_{H} p_{H}}{\left(1-p_{L}\right) a_{L} p_{L}}-1}\right] \Delta e$. In this case, the employer prefers to reward the employee in the appeals process. Hence, the employer delivers no payment for superior performance in the initial stage, but a large payment for superior performance in the appeals process. Doing so best limits the employee's rent from evaluation errors. Meanwhile, the employer delivers a positive payment for minimum performance in the initial stage, but no payment for minimum performance in the appeal process. Doing so deters the employee from appealing when he has delivered minimum performance.

As the initial evaluation becomes more accurate, the employee's performance is less likely found to be minimum when he has delivered superior performance, but more likely so when he has delivered minimum performance. Therefore, although it improves 
the accuracy in the appeals process, increased accuracy of the initial evaluation reduces an industrious employee's but increases a dishonest employee's access to the appeal process. Consequently, increased accuracy of the initial evaluation can increase the employer's cost of securing compliance.

In contrast, the employer's expected cost of securing compliance and loss of justice always decreases in the accuracy of the appeals process. When $\frac{a_{H}}{a_{L}} \geq\left[1+\frac{\Delta e}{e\left(\alpha_{L}, Q_{L}\right)}\right] \frac{\left(1-p_{L}\right) p_{L}}{\left(1-p_{H}\right) p_{H}}$, the employer in expectation delivers the second-best payment.

\subsection{A costly appeals process.}

When the appeal process is costly, the employer's welfare will depend on the cost of the process, the allocation of the cost between the employer and the appellant, and the accuracy of the appeals process. Proposition 2 characterizes the optimal cost allocation between parties in an appeals process.

Proposition 2. In the appeals setting, it is desirable to impose all the cost of the appeals process on the appellant. ${ }^{5}$

The intuition underlying Proposition 2 is straightforward. Since the investigation in the appeals process is more like to reveal superior performance when the appellant has delivered superior performance than when he has delivered minimum performance, an employee who has delivered superior performance receives higher expected payment from appealing than one who has not. Since the employee appeals only if his expected gain from appealing is larger than his cost of appealing, imposing a larger share of the 
cost on the appellant helps prevent an employee who has delivered only minimum performance from appealing. Therefore, the employer always prefers the appellant to bear all the costs of the appeals process, which can be viewed as a forfeitable bond that must be posted in order to appeal. This forfeitable bond relaxes the limited liability constraint in the appeals process.

Although Proposition 2 suggests that it is optimal for the principal to impose all the cost of the appeals process on the appellant, in many settings, especially administrative and regulatory settings, the principal is often restricted from doing so for political or social reasons. So I will consider $r$ as exogenous for the employer in the model and examine how $r$ affects the properties of an appeals process.

Proposition 3 characterizes the upper bound of the cost of the appeals process for implementing the appeals process to be optimal.

Proposition 3: The employer optimally denies any appeals when $C>\frac{p_{L} \Delta e-\left(p_{H}-p_{L}\right) e\left(\alpha_{L}, Q_{L}\right)}{\mu_{H}\left(1-p_{H}\right)\left(p_{H}-p_{L}\right)}+a_{H} p_{H} J$

The intuition behind Proposition 3 is the following. The maximum value of an appeals process is its effect on justice plus the difference between the employer's expected payment in the second-best contract and that in an optimal contract without the appeals process, which is $\frac{p_{L} \Delta e-\left(p_{H}-p_{L}\right) e\left(\alpha_{L}, Q_{L}\right)}{p_{H}-p_{L}}+\mu_{H}\left(1-p_{H}\right) a_{H} p_{H} J$. The employer's expected cost of implementing the appeals process is $\mu_{H}\left(1-p_{H}\right) C$, where $\mu_{H}\left(1-p_{H}\right)$ is the probability that an appeal actually occurs. Notice that although the employer may impose part of the cost on the appellant, she must compensate the high- 
productivity employee's cost of appealing through rewards in the appeals process in order to induce superior performance from him. Therefore, when $C>\frac{p_{L} \Delta e-\left(p_{H}-p_{L}\right) e\left(\alpha_{L}, Q_{L}\right)}{\mu_{H}\left(1-p_{H}\right)\left(p_{H}-p_{L}\right)}+a_{H} p_{H} J$, the employer's cost of implementing the appeals process outweighs her benefit from the appeals process and it is not optimal to implement an appeals process no matter how accurate it is.

When $C \leq \frac{p_{L} \Delta e-\left(p_{H}-p_{L}\right) e\left(\alpha_{L}, Q_{L}\right)}{\mu_{H}\left(1-p_{H}\right)\left(p_{H}-p_{L}\right)}+a_{H} p_{H} J$, the properties of the optimal contract depend upon the accuracy and the cost of the appeals process. Table 1 identifies five main categories regarding the accuracy and the cost of the appeals process. The properties of the optimal appeals process are different in each of these categories.

[Table 1. Condition of the Appeals Process]

When the High-accuracy Condition, Medium-accuracy/High-cost condition, or Low-accuracy/High-cost condition holds, limits on liability are not constraining because of the high accuracy or the high cost of the appeals process. Consequently, the employee receives the same expected payment as when the evaluation is perfect.

In contrast, limits on liability are constraining when the Low-accuracy/Low-cost Condition or Medium-accuracy/Low-cost Condition holds. Proposition 4 and Proposition 5 present the properties of the optimal appeals process under the Low-accuracy/Low-cost Condition and the Medium-accuracy/ Low-cost Condition, respectively.

Proposition 4: When the Low-accuracy /Low-cost Condition holds, the solution to $[\mathrm{P}-\mathrm{A}]$ has the following features: 
(i) An employee claiming high-productivity receives a positive payment when the initial evaluation reveals superior performance but no payment when it reveals minimum performance;

(ii) The employee receives a positive payment for superior performance but no payment for minimum performance in the appeal process;

(iii) The employer's welfare increases as the cost of the appeals process increases when she can impose a large share of the cost on the appellant;

(iv) When the employer cannot impose a large share of the cost of appeals on the appellant, she implements an appeal process only if her concern for justice is substantial.

In the case of a costless appeals process, it has been shown that implementing an appeals process increases the likelihood of rewarding a shirking employee and therefore increases the employer's expected payment when $\frac{a_{H}}{a_{L}}<\frac{1-p_{L}}{1-p_{H}}$. Hence, when the employer's concern for justice is minimal, the employer should reward the employee in the initial stage and preclude appeals by offering no reward if an appeal is lodged. However, when the appeals process is costly, the cost of the appeals process born by the appellant functions as a forfeitable bond, which relaxes the limited liability constraint in the appeals process. The appeals process becomes useful for the employer, even if justice is not a concern, because of the associated enhanced ability to penalize the employee when he is found to have delivered minimum performance in the appeals process. The employer makes full use of the appeals process by delivering no payment (the appellant's bond is forfeited) when minimum performance is found but delivering a positive payment 
when superior performance is found in the appeals process. This positive payment is increased up to the point where the employee's expected profit from appealing (the difference between expected payment and expected cost of appealing) is zero if he has delivered minimum performance. This ensures an employee who has delivered minimum performance has no (strict) incentive to appeal. After this point, the limited liability constraint in the appeals process binds, and the employer delivers the rest of the payment in the initial stage as in the costless appeals process. Hence, when the employee claims to be a high-productivity employee, the employer delivers to him a positive payment for superior performance but no payment for minimum performance, both in the initial stage and in the appeals process.

The employer's expected cost of implementing the appeals process has been shown to be $\mu\left(1-p_{H}\right) C$. In expectation the appeals process enables the employer to reduce the employee's rent by $\frac{\left(1-p_{H}\right)\left(\frac{a_{H} p_{H}}{a_{L} p_{L}}-1\right)(1-r) C}{\frac{p_{H}}{p_{L}}-1}$. Therefore, when $r<1-\mu_{H}\left(\frac{p_{H}}{p_{L}}-1\right) /\left(\frac{a_{H} p_{H}}{a_{L} p_{L}}-1\right)$, the employer's expected payment decreases as the cost of the appeals process increases. Otherwise, the appeal process increases the employer's expected total expenditure (the expected payment plus the expected cost of implementing the appeals process) and the employer's welfare decreases as the cost of the appeals process increases. In this case, the employer implements an appeals process only if her concern for justice is substantial. 
Proposition 5: When the Medium-accuracy/Low-Cost Condition holds, the solution to [P-A] has the following features:

(i) An employee claiming high-productivity receives no payment when the initial evaluation reveals superior performance, but a positive payment when it reveals minimum performance;

(ii) The employer delivers a positive payment for minimum performance in the initial stage, but no payment for minimum performance in the appeal process;

(iii) The employer's welfare increases in the cost of the appeals process when she can impose a large share of the cost on the appellant;

(iv) When the employer cannot impose a large share of the cost of appeals on the appellant, she implements a high cost appeal process only if her concern for justice is substantial.

(v) Increased accuracy of the initial evaluation can reduce the employer's welfare.

When $\frac{a_{H}}{a_{L}}>\frac{1-p_{L}}{1-p_{H}}$, it has been shown that implementing an appeals process increases the likelihood of rewarding superior performance. Consequently, the employer prefers to reward superior performance in the appeals process. Doing so best limits the employee’s rent from evaluation errors. Meanwhile, the employer compensates minimum performance in the initial stage to deter an employee who has delivered minimum performance from appealing.

The cost of the appeals process imposed on the appellant helps deter a shirking employee from appealing and therefore enables the employer to reward superior performance in the appeals process. Consequently, the employer can reduce the 
employee's rent by $\left[\frac{\left(p_{H}-p_{L}\right) a_{L} p_{L}}{\left(1-p_{H}\right) a_{H} p_{H}-\left(1-p_{L}\right) a_{L} p_{L}}+1\right]\left(1-p_{L}\right)(1-r) C$. The employer's expected cost of implementing the appeals process has been shown to be $\mu_{H}\left(1-p_{H}\right) C$. When $r$ is small so that $\left[\frac{\left(p_{H}-p_{L}\right) a_{L} p_{L}}{\left(1-p_{H}\right) a_{H} p_{H}-\left(1-p_{L}\right) a_{L} p_{L}}+1\right]\left(1-p_{L}\right)(1-r)>\mu_{H}\left(1-p_{H}\right)$, the employer's welfare increases as the cost of the appeals process increases. Otherwise, the employer's welfare decreases as the cost of the appeals process increases. When the appeals process becomes sufficiently costly, the employer implements an appeals process only if her concern for justice is substantial.

As $\frac{a_{H}}{a_{L}}$ increases, the employer is less likely to make evaluation errors in the appeals process, which reduces the employee's rent from evaluation errors and the loss of justice. Therefore, the employer's welfare increases as the accuracy of the appeals

process increases. However, the employer's welfare can decrease in $\frac{p_{H}}{p_{L}}$. The reason is the same as in the case where the appeals process is costless. Increased accuracy of the initial evaluation reduces an industrious employee's but increases a dishonest employee's access to the appeal process. Therefore, increased accuracy of initial evaluation restricts the employer's ability to reward different performance levels differentially through the appeals process, and therefore can reduce the employer's welfare.

\section{The appeals process versus auditing}

Optimal auditing policies in the principal-agent framework have been analyzed in the economics literature, for example in Townsend (1979), Baiman and Demski (1980), and 
Dye (1986). This section discusses how the appeals process differs from an optimal auditing strategy and under what conditions the employer prefers an appeals process to auditing. Observation 4 presents the optimal auditing policy in this setting if justice is not a concern.

Observation 4. The employer audits an employee's performance only when he claims to have high-productivity and is initially found to have delivered superior performance. The employee is rewarded only if the auditing also reveals superior performance.

This auditing strategy is optimal because it maximizes the probability of penalizing a shirking employee and minimizes the employer's cost of securing compliance in the presence of limited liabilities. Suppose the audit is as accurate as the appeals process. Let $T_{H}^{i}$ and $T_{L}^{i}$ denote the payments when the audit reveals superior performance and minimum performance, respectively. When the employer is concerned for justice, her welfare under the auditing strategy is

$$
\mu_{H}\left\{V\left(Q_{H}\right)-p_{H}\left[a_{H} p_{H} T_{H}^{i}+\left(1-a_{H} p_{H}\right)\left(T_{L}^{i}+J\right)\right]-\left(1-p_{H}\right)\left(T_{L}^{H}+J\right)\right\}+\mu_{L}\left\{V\left(Q_{L}\right)-T^{L}\right\} .
$$

The expected loss of justice due to evaluation errors under this strategy is $\mu_{H}\left[p_{H}\left(1-a_{H} p_{H}\right)+\left(1-p_{H}\right)\right] J$ compared to $\mu_{H}\left(1-p_{H}\right) J$ when the audit is not implemented, i.e. the auditing strategy aggravates the loss of justice. The reason is that in equilibrium a high-productivity employee always delivers superior performance. Therefore, under the "optimal" auditing strategy, the audit in equilibrium is triggered byand may mistakenly reverse-correct initial evaluations. When the employer's concern for 
justice is substantial, the above auditing strategy cannot be optimal even though it reduces the employer's cost of securing compliance. ${ }^{5}$

In contrast, the appeals process in equilibrium is triggered by-and potentially reverses-incorrect initial evaluations as shown in earlier analysis. Furthermore, the employer always weakly prefers the optimal appeals process to an auditing strategy which audits the employee's performance when he claims to have high productivity and is initially found to have delivered minimum performance. This is because, in the optimal appeals process, the employee appeals only when he has actually delivered superior performance. Compared to the auditing strategy, the optimal appeals process saves the costs of auditing when the initial evaluation is correct. I sum up these observations in Observation 5.

Observation 5. When the concern for justice is substantial, the employer always weakly prefers an appeals process to an auditing strategy.

\section{Conclusion}

This paper examines the role of the appeals process in securing compliance and in promoting justice. Four primary observations emerge from the analysis. First, the merit of the appeal process largely depends on the employer's concern for justice. Second, when the appeals process is sufficiently accurate, an employee may be paid more initially for minimum performance than for superior performance. Third, increased initial observation accuracy may reduce the employer's welfare. Fourth, the appellant bears all the cost of appealing in an optimal appeals process and the employer's welfare can increase as the cost of the appealing increases. 
The paper emphasizes the merit of the appeals process in securing compliance and in enhancing justice through error corrections. This is not to deny the importance of other possible merits of the appeals process. For example, Sheppard (1985) found that the capacity to appeal a decision itself vastly improved the perceived fairness of a procedure. Research on justice (e.g., Folger, 1987; Greenberg, 1986; Paese, Lind, \& Kanfer, 1988) has found that perceived procedure fairness affects perception of justice as well as subsequent attitudes, regardless of the fairness of the decision itself, in many organizational decision contexts and is particular relevant to performance evaluation.

This study also abstracts from several factors that might be included in future research. First, the study assumes that the employer is able to commit to the appeals process. When the employer is not able to commit, there will exist no pure strategy separating equilibrium. This is because the employer has no incentive to carry out an investigation in the appeals process if only an employee who has delivered superior performance appeals. ${ }^{7}$ Second, this study focuses on the role of the appeals process in securing compliance with a given (exogenous) set of performance standards. How optimal standards might vary when appeals are permitted warrants further study. 


\section{FOOTNOTES}

1. In other words, $e\left(\alpha_{H}, Q_{H}\right)-e\left(\alpha_{H}, Q_{L}\right)<V\left(Q_{H}\right)-V\left(Q_{L}\right)<e\left(\alpha_{L}, Q_{H}\right)-e\left(\alpha_{L}, Q_{L}\right)$. Therefore, it is desirable to induce superior performance from a high-productivity employee and minimum performance from a low-productivity employee.

2. See Dai (2004) for a detailed formulation and proof of the employer's problem.

3. The employer is assumed to be able to commit to her proposed mechanism as in standard principal-agent models.

4. Equivalently, the employer can make the payments in the appeals process unattractive to the worker so that no appeals will occur.

5. Note the cost of the appeals process can be non-monetary resources such as time and effort needed to collect supporting evidences. So it suggests that it is optimal to impose a larger burden of proof on the appellant. It also suggests that, in a regulatory setting, the fact that regulatory hearings usually consume considerable time and resources does not necessarily imply that the process is inefficient. This offers another explanation for "regulatory bureaucracy". Sappington (1986) shows that regulatory bureaucracy, which makes the regulatory agency difficult to discern the firm's costs, creates incentives for the firm to reduce costs when the regulator does not have commitment power.

6. When the auditing is costly, the optimal auditing strategy would be randomly auditing an employee's performance when he claims to have high-productivity and is initially found to have delivered superior performance. The above arguments would still hold.

7. Khalil (1997) analyses a principal-agent model where the principal cannot commit to an auditing policy. 


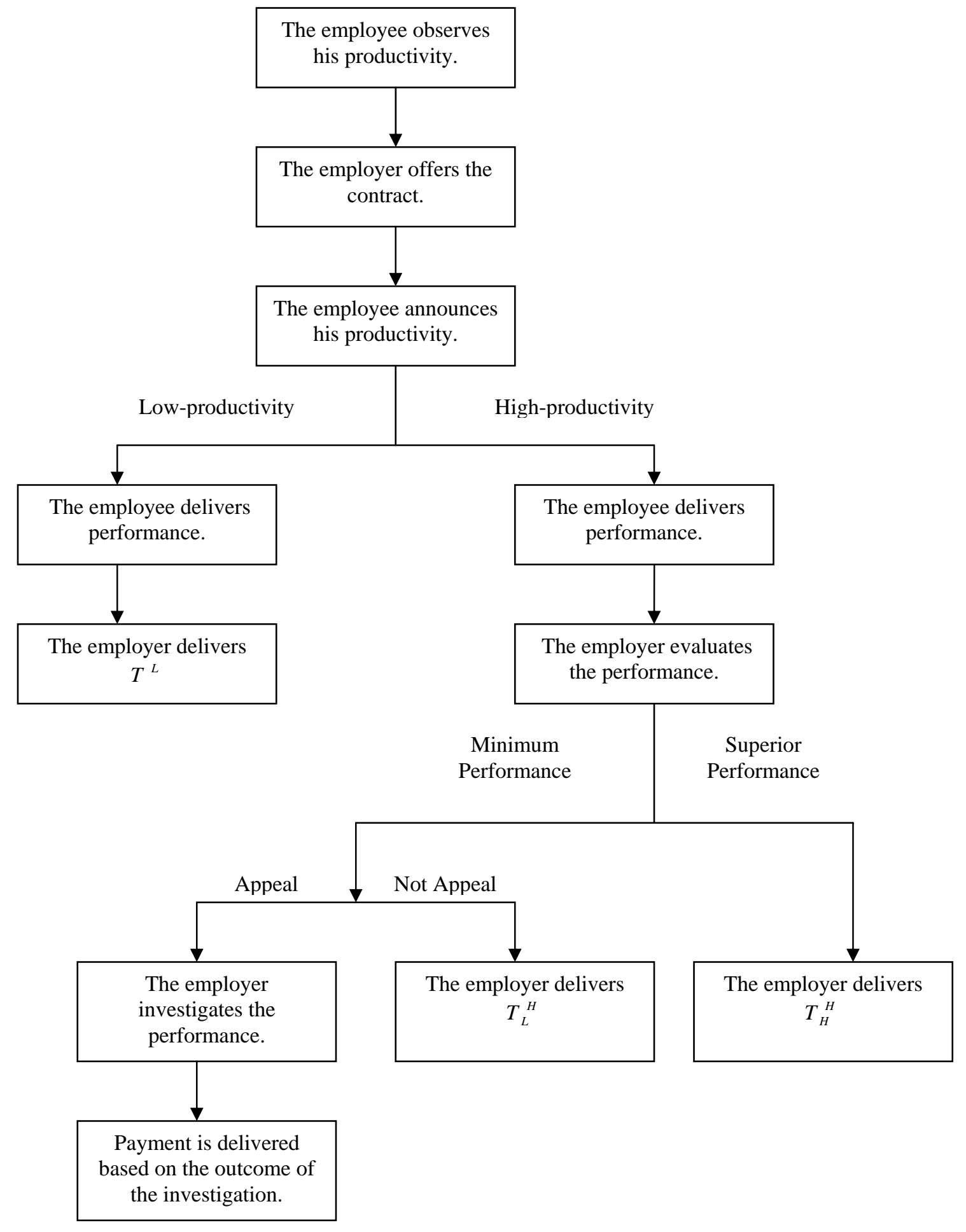

Figure 1. Sequence of actions 


\begin{tabular}{|c|c|c|}
\hline Conditions & Accuracy & Cost \\
\hline \multirow[t]{2}{*}{$\begin{array}{l}\text { Low-accuracy/Low- } \\
\text { cost Condition }\end{array}$} & $\frac{a_{H}}{a_{L}}<\frac{1-p_{L}}{1-p_{H}}$ & \multirow{2}{*}{$C<\frac{\left[e\left(\alpha_{H}, Q_{H}\right)-e\left(\alpha_{H}, Q_{L}\right)\right]-\left[\frac{p_{H}}{p_{L}}-1\right] e\left(\alpha_{L}, Q_{L}\right)}{\left(\frac{a_{H} p_{H}}{a_{L} p_{L}}-1\right)\left(1-p_{H}\right)(1-r)}$} \\
\hline & & \\
\hline \multirow[t]{2}{*}{$\begin{array}{l}\text { Low-accuracy/High- } \\
\text { cost Condition }\end{array}$} & \multirow[t]{2}{*}{$\frac{a_{H}}{a_{L}}<\frac{1-p_{L}}{1-p_{H}}$} & \multirow{2}{*}{$\frac{\Delta e-\left[\frac{p_{H}}{p_{L}}-1\right] e\left(\alpha_{L}, Q_{L}\right)}{\left(\frac{a_{H} p_{H}}{a_{L} p_{L}}-1\right)\left(1-p_{H}\right)(1-r)}$} \\
\hline & & \\
\hline \multirow{2}{*}{$\begin{array}{l}\text { Medium- } \\
\text { accuracy/Low-cost } \\
\text { Condition }\end{array}$} & \multirow[t]{2}{*}[1+\frac{\Deltae}{e(\alpha_{L},Q_{L})}]{$\frac{\left(1-p_{L}\right) p_{L}}{\left(1-p_{H}\right) p_{H}}>\frac{a_{H}}{a_{L}}>\frac{1-p_{L}}{1-p_{H}}$} & \multirow{2}{*}{$C<\frac{\Delta e-\left[\frac{\left(1-p_{H}\right) a_{H}}{\left(1-p_{L}\right) a_{L}}-1\right] e\left(\alpha_{L}, Q_{L}\right)}{\left(\frac{a_{H} p_{H}}{a_{L} p_{L}}-1\right)\left(1-p_{H}\right)(1-r)}$} \\
\hline & & \\
\hline \multirow{2}{*}{$\begin{array}{l}\text { Medium- } \\
\text { accuracy/High-cost } \\
\text { Condition }\end{array}$} & \multirow[t]{2}{*}[1+\frac{\Deltae}{e(\alpha_{L},Q_{L})}]{$\frac{\left(1-p_{L}\right) p_{L}}{\left(1-p_{H}\right) p_{H}}>\frac{a_{H}}{a_{L}}>\frac{1-p_{L}}{1-p_{H}}$} & \multirow{2}{*}{$C \geq \frac{\Delta e-\left[\frac{\left(1-p_{H}\right) a_{H}}{\left(1-p_{L}\right) a_{L}}-1\right] e\left(\alpha_{L}, Q_{L}\right)}{\left(\frac{a_{H} p_{H}}{a_{L} p_{L}}-1\right)\left(1-p_{H}\right)(1-r)}$} \\
\hline & & \\
\hline $\begin{array}{l}\text { High-accuracy } \\
\text { Condition }\end{array}$ & $\frac{a_{H}}{a_{L}} \geq\left[1+\frac{\Delta e}{e\left(\alpha_{L}, Q_{L}\right)}\right] \frac{\left(1-p_{L}\right) p_{L}}{\left(1-p_{H}\right) p_{H}}$ & \\
\hline
\end{tabular}

Table 1. Conditions of the Appeal Process 


\section{Appendix}

\section{The Solution to [P-A]:}

\section{A costless appeals process:}

It can be readily shown that constraints IRH, ICH1, ICL1, ICH2, ICL3, LLL, and LLAH are redundant. Therefore, the Lagrangian of this problem is as follows:

$$
\begin{aligned}
\lambda= & \mu_{H}\left\{V\left(Q_{H,}\right)-p_{H} T_{H}^{H}-\left(1-p_{H}\right)\left[a_{H} p_{H} T_{H}^{A}+\left(1-a_{H} p_{H}\right)\left(T_{L}^{A}+J\right)\right]\right\}+\mu_{L}\left\{V\left(Q_{L}\right)-T^{L}\right\} \\
& +\lambda_{0}\left\{T^{L}-\left[p_{L} T_{H}^{H}+\left(1-p_{L}\right) T_{L}^{H}\right]\right\}+\lambda_{1}\left\{T^{L}-e\left(\alpha_{L}, Q_{L}\right)\right\} \\
& +\lambda_{2}\left\{p_{H} T_{H}^{H}+\left(1-p_{H}\right)\left[a_{H} p_{H} T_{H}^{A}+\left(1-a_{H} p_{H}\right) T_{L}^{A}\right]-e\left(\alpha_{H}, Q_{H}\right)-\left[T^{L}-e\left(\alpha_{H}, Q_{L}\right)\right]\right\} \\
& +\lambda_{3}\left\{T_{L}^{H}-\left[a_{L} p_{L} T_{H}^{A}+\left(1-a_{L} p_{L}\right) T_{L}^{A}\right]\right\}_{L}+\lambda_{4} T_{H}^{H}+\lambda_{5} T_{H}^{A}+\lambda_{6} T_{L}^{A}
\end{aligned}
$$

The first order conditions are:

$$
\begin{aligned}
& \lambda_{T_{H}^{H}}=-\mu_{H} p_{H}-\lambda_{0} p_{L}+\lambda_{2} p_{H}+\lambda_{4}=0 \\
& \lambda_{T_{L}^{H}}=-\lambda_{0}\left(1-p_{L}\right)+\lambda_{3}=0 \\
& \lambda_{T^{L}}=-\mu_{L}+\lambda_{0}+\lambda_{1}-\lambda_{2}=0 \\
& \lambda_{T_{H}^{A}}=-\mu_{H}\left(1-p_{H}\right) a_{H} p_{H}+\lambda_{2}\left(1-p_{H}\right) a_{H} p_{H}-\lambda_{3} a_{L} p_{L}+\lambda_{5}=0 \\
& \lambda_{T_{L}^{A}}=-\mu_{H}\left(1-p_{H}\right)\left(1-a_{H} p_{H}\right)+\lambda_{2}\left(1-p_{H}\right)\left(1-a_{H} p_{H}\right)-\lambda_{3}\left(1-a_{L} p_{L}\right)+\lambda_{6}=0
\end{aligned}
$$

The following seven cases are to be analyzed:

Case I: $\lambda_{3}=0$ and $\lambda_{4}=0$;

Case II: $\lambda_{3}=0$ and $\lambda_{4}>0$;

Case III: $\lambda_{3}>0, \lambda_{4}=0, \lambda_{5}=0$ and $\lambda_{6}>0$;

Case IV: $\lambda_{3}>0, \lambda_{4}=0, \lambda_{5}=0$ and $\lambda_{6}=0$; 
Case V: $\lambda_{3}>0, \lambda_{4}=0, \lambda_{5}>0$ and $\lambda_{6}>0$;

Case VI: $\lambda_{3}>0, \lambda_{4}=0, \lambda_{5}>0$ and $\lambda_{6}=0$;

Case VII: $\lambda_{3}>0$ and $\lambda_{4}>0$.

Among the seven cases, Case II, Case IV, and Case VI can be ruled out by contradictions, and therefore only Case I, Case III, Case V and Case VII are valid cases.

Case I: $\lambda_{3}=0$ and $\lambda_{4}=0$;

Substituting $\lambda_{3}=0$ and $\lambda_{4}=0$ into (A2), (A3) and (A4) and jointly solving these three equations provides $\lambda_{1}=1$ and $\lambda_{2}=\mu_{H}$. Substituting $\lambda_{1}=1, \lambda_{2}=\mu_{H}, \lambda_{3}=0$ and $\lambda_{4}=0$ into (A5) and (A6) provides $\lambda_{5}=0$ and $\lambda_{6}=0$.

$\lambda_{1}=1$ and $\lambda_{2}=\mu_{H}$ imply that the constraints IRL and ICH are binding. Therefore,

$$
\begin{aligned}
& T^{L}=e\left(\alpha_{L}, Q_{L}\right) \text {; and } \\
& p_{H} T_{H}^{H}+\left(1-p_{H}\right)\left[a_{H} p_{H} T_{H}^{A}+\left(1-a_{H} p_{H}\right) T_{L}^{A}\right]=\Delta e+e\left(\alpha_{L}, Q_{L}\right) .
\end{aligned}
$$

Equations (A7) and (A8) indicates the employer is able to in expectation deliver the second-best payment to the employee. For this case to be true, we must have

$$
\frac{\left(1-p_{H}\right) a_{H} p_{H}}{\left(1-p_{L}\right) a_{L} p_{L}} \geq 1+\frac{\Delta e}{e\left(\alpha_{L}, Q_{L}\right)} .
$$

Since we assume $\frac{p_{H}}{p_{L}}<1+\frac{\Delta e}{e\left(\alpha_{L}, Q_{L}\right)}$, this case exists only if

$$
\frac{a_{H}}{a_{L}}>\frac{1-p_{L}}{1-p_{H}} .
$$

Case III: $\lambda_{3}>0, \lambda_{4}=0, \lambda_{5}=0$ and $\lambda_{6}>0$; 
From (A5), we have

$$
\lambda_{3}=\left(\lambda_{2}-\mu_{H}\right)\left(1-p_{H}\right) \frac{a_{H} p_{H}}{a_{L} p_{L}} .
$$

Jointly solving (A2) and (A3) provides

$$
\lambda_{3}=\left(\lambda_{2}-\mu_{H}\right)\left(1-p_{L}\right) \frac{p_{H}}{p_{L}}
$$

Since $\lambda_{3}>0$ and $\lambda_{2}-\mu_{H} \neq 0$. Therefore,

$$
\frac{p_{H}}{p_{L}}=\frac{\left(1-p_{H}\right) * a_{H} p_{H}}{\left(1-p_{L}\right) * a_{L} p_{L}}
$$

In this case, the ratio of the likelihoods of rewarding an honest employee and a shirking employee are the same with or without the appeals process. Hence, the employer delivers the same expected payment with or without the appeals process.

Case V: $\lambda_{3}>0, \lambda_{4}=0, \lambda_{5}>0$ and $\lambda_{6}>0$;

Jointly solving (A2) and (A3) provides

$$
\lambda_{3}=\left(\lambda_{2}-\mu_{H}\right)\left(1-p_{L}\right) \frac{p_{H}}{p_{L}}
$$

(A5) provides

$$
\lambda_{5}=\lambda_{3} a_{L} p_{L}-\left(\lambda_{2}-\mu_{H}\right)\left(1-p_{H}\right) a_{H} p_{H}
$$

$\lambda_{5}>0$ requires $\frac{a_{H}}{a_{L}}<\frac{1-p_{L}}{1-p_{H}}$. In this case, the ratio of the likelihoods of rewarding an honest employee and a shirking employee is even lower when the appeals process is incorporated. Hence, the employer delivers a larger expected payment with the appeals process. 
Case VII: $\lambda_{3}>0$ and $\lambda_{4}>0$.

Since $\lambda_{4}>0, T_{H}^{H}=0$. Therefore, $T_{H}^{A}>0$ and $\lambda_{5}=0$. Substituting $\lambda_{5}=0$ into (A5) provides

$$
\frac{a_{L} p_{L}}{a_{H} p_{H}} \lambda_{3}=\left(\lambda_{2}-\mu_{H}\right)\left(1-p_{H}\right) .
$$

Substituting (A16) into (A6) provides

$$
\lambda_{6}=\left[\left(1-a_{L} p_{L}\right)-\left(1-a_{H} p_{H}\right) \frac{a_{L} p_{L}}{a_{H} p_{H}}\right] \lambda_{3}>0 .
$$

$\lambda_{6}>0$ suggests that $T_{L}^{A}=0$. In addition, $\lambda_{3}>0$ suggests that $T_{L}^{H}=a_{L} T_{H}^{A}$.

Substituting $T_{H}^{H}=0, T_{L}^{A}=0$ and $T_{L}^{H}=a_{L} T_{H}^{A}$ into constraint ICH3 provides

$$
T_{H}^{A}=\frac{\Delta e}{\left(1-p_{H}\right) a_{H} p_{H}-\left(1-p_{L}\right) a_{L} p_{L}} .
$$

Constraints IRL and ICL2 require

$$
T_{H}^{A} \geq \frac{e\left(\alpha_{L}, Q_{L}\right)}{\left(1-p_{L}\right) a_{L} p_{L}}
$$

For (A19) to hold, we must have

$$
\frac{\Delta e}{\left(1-p_{H}\right) a_{H} p_{H}-\left(1-p_{L}\right) a_{L} p_{L}} \geq \frac{e\left(\alpha_{L}, Q_{L}\right)}{\left(1-p_{L}\right) a_{L} p_{L}} .
$$

(A20) indicates $\lambda_{1}=0$. Substituting $\lambda_{1}=0$ into (A2), (A3), (A4), and (A5) and jointly solving these equations provides

$$
\lambda_{4}=\frac{p_{L}\left(1-p_{H}\right) a_{H} p_{H}-p_{H}\left(1-p_{L}\right) a_{L} p_{L}}{\left(1-p_{H}\right) a_{H} p_{H}-\left(1-p_{L}\right) a_{L} p_{L}} .
$$

Since $\lambda_{4}>0$, we have 


$$
\frac{a_{H}}{a_{L}}>\frac{1-p_{L}}{1-p_{H}} .
$$

Substituting (A18) into the principal's objective function provides

$$
W=\mu_{H} V\left(Q_{H}\right)+\mu_{L} V\left(Q_{L}\right)-\left[\mu_{H}+\frac{2 \mu_{H}-1}{\frac{\left(1-p_{H}\right) a_{H} p_{H}}{\left(1-p_{L}\right) a_{L} p_{L}}-1}\right] \Delta e-\mu_{H}\left(1-p_{H}\right)\left(1-a_{H} p_{H}\right) h .
$$

(A23) suggests that the employer's expected payment is increasing in $p_{H}$ and $p_{L}$ and decreasing in $\frac{a_{H}}{a_{L}}$.

\section{A costly appeals process.}

The Lagrangian of this problem is as follows.

$$
\begin{aligned}
\lambda= & \mu_{H}\left\{V\left(Q_{H}\right)-p_{H} T_{H}^{H}-\left(1-p_{H}\right)\left[a_{H} p_{H} T_{H}^{A}+\left(1-a_{H} p_{H}\right)\left(T_{L}^{A}+J\right)+r C\right]\right\} \\
& +\mu_{L}\left\{V\left(Q_{L}\right)-T^{L}\right\}+\lambda_{0}\left\{T^{L}-\left[p_{L} T_{H}^{H}+\left(1-p_{L}\right) T_{L}^{H}\right]\right\}+\lambda_{1}\left\{T^{L}-e\left(\alpha_{L}, Q_{L}\right)\right\} \\
& +\lambda_{2}\left\{p_{H} T_{H}^{H}+\left(1-p_{H}\right)\left[a_{H} p_{H} T_{H}^{A}+\left(1-a_{H} p_{H}\right) T_{L}^{A}-(1-r) C\right]-e\left(\alpha_{H}, Q_{H}\right)\right. \\
& \left.-\left[T^{L}-e\left(\alpha_{H}, Q_{L}\right)\right]\right\}+\lambda_{3}\left\{T_{L}^{H}-\left[a_{L} p_{L} T_{H}^{A}+\left(1-a_{L} p_{L}\right) T_{L}^{A}-(1-r) C\right]\right\} \\
& +\lambda_{4} T_{H}^{H}+\lambda_{5} T_{H}^{A}+\lambda_{6} T_{L}^{A}+\lambda_{7} T_{L}^{H}
\end{aligned}
$$

The first order conditions are:

$$
\begin{aligned}
& \lambda_{T_{H}^{H}}=-\mu_{H} p_{H}-\lambda_{0} p_{L}+\lambda_{2} p_{H}+\lambda_{4}=0 \\
& \lambda_{T_{L}^{H}}=-\lambda_{0}\left(1-p_{L}\right)+\lambda_{3}+\lambda_{7}=0 \\
& \lambda_{T^{L}}=-\mu_{L}+\lambda_{0}+\lambda_{1}-\lambda_{2}=0
\end{aligned}
$$




$$
\begin{aligned}
& \lambda_{T_{H}^{A}}=-\mu_{H}\left(1-p_{H}\right) a_{H} p_{H}+\lambda_{2}\left(1-p_{H}\right) a_{H} p_{H}-\lambda_{3} a_{L} p_{L}+\lambda_{5}=0 \\
& \lambda_{T_{L}^{A}}=-\mu_{H}\left(1-p_{H}\right)\left(1-a_{H} p_{H}\right)+\lambda_{2}\left(1-p_{H}\right)\left(1-a_{H} p_{H}\right)-\lambda_{3}\left(1-a_{L} p_{L}\right)+\lambda_{6}=0 \\
& \lambda_{r}=-\mu_{H}\left(1-p_{H}\right) C+\lambda_{2}\left(1-p_{H}\right) C-\lambda_{3} C>0, r>0, \& r \lambda_{r}=0
\end{aligned}
$$

There are three valid cases to be analyzed, and all other cases can be ruled out by contradictions.

Case I: $\lambda_{3}=0, \lambda_{4}=0$ and $\lambda_{7}=0$;

Substituting $\lambda_{3}=0, \lambda_{4}=0$ and $\lambda_{7}=0$ into (A25), (A26) and (A27) and jointly solving these three equations provides $\lambda_{1}=1$ and $\lambda_{2}=\mu_{H}$. Substituting $\lambda_{2}=\mu_{H}$ and $\lambda_{3}=0$ into (A28) and (A29) provides $\lambda_{5}=0$ and $\lambda_{6}=0$.

$$
\lambda_{1}=1 \text { and } \lambda_{2}=\mu_{H} \text { imply that the constraints IRL and ICH3 are binding. }
$$

Therefore,

$$
\begin{aligned}
& T^{L}=e\left(\alpha_{L}, Q_{L}\right) \text {; and } \\
& p_{H} T_{H}^{H}+\left(1-p_{H}\right)\left[a_{H} p_{H} T_{H}^{A}+\left(1-a_{H} p_{H}\right) T_{L}^{A}-(1-r) C\right]=\Delta e+e\left(\alpha_{L}, Q_{L}\right) .
\end{aligned}
$$

Equations (A31) and (A32) indicate the employee in expectation receives the second-best payoff. Note that equation (A30) always holds, in other words, $r$ has no effect on the result.

Case II: $\lambda_{3}>0, \lambda_{4}=0, \lambda_{5}=0, \lambda_{6}>0$ and $\lambda_{7}>0$;

$$
\lambda_{7}>0 \text { indicates } T_{L}^{H}=0 . \quad \lambda_{6}>0 \text { indicates } T_{L}^{A}=0 \text {. Furthermore, } \lambda_{3}>0
$$

indicates $T_{L}^{H}=a_{L} p_{L} T_{H}^{A}-(1-r) C$. Therefore,

$$
T_{H}^{A}=\frac{(1-r) C}{a_{L} p_{L}} .
$$


Substituting $\lambda_{5}=0$ into (A28) provides

$$
\lambda_{2}\left(1-p_{H}\right) a_{H} p_{H}=\left(1-p_{H}\right) a_{H} p_{H}+\lambda_{3} a_{L} p_{L}
$$

which implies $\lambda_{2}>0$ and constraint ICH3 is binding. Therefore,

$$
p_{H} T_{H}^{H}+\left(1-p_{H}\right)\left[a_{H} p_{H} T_{H}^{A}-(1-r) C\right]-e\left(\alpha_{H}, Q_{H}\right)=T_{L}-e\left(\alpha_{H}, Q_{L}\right)
$$

Substituting $\lambda_{4}=0$ into (A25) provides $\lambda_{0}=\frac{\lambda_{2}-\mu_{H}}{p_{L}}$.

Therefore, $\lambda_{0}>0$ and $T^{L}=p_{L} T_{H}^{H}$.

Therefore,

$$
p_{H} T_{H}^{H}+\left(1-p_{H}\right)\left[a_{H} p_{H} T_{H}^{A}-(1-r) C\right]-e\left(\alpha_{H}, Q_{H}\right)=p_{L} T_{H}^{H}-e\left(\alpha_{H}, Q_{L}\right)
$$

Constraint ICL requires $T_{H}^{H} \geq \frac{e\left(\alpha_{L}, Q_{L}\right)}{p_{L}}$. Assume

$$
T_{H}^{H}=\frac{e\left(\alpha_{L}, Q_{L}\right)}{p_{L}} .
$$

Substituting (A37) into (A36) together provides

$$
T_{H}^{A}=\frac{\Delta e-\left[\frac{p_{H}}{p_{L}}-1\right] e\left(\alpha_{L}, Q_{L}\right)+\left(1-p_{H}\right)(1-r) C}{\left(1-p_{H}\right) a_{H} p_{H}} .
$$

(A33) and (A38) together require

$$
C_{A}=\frac{\left[e\left(\alpha_{H}, Q_{H}\right)-e\left(\alpha_{H}, Q_{L}\right)\right]-\left[\frac{p_{H}}{p_{L}}-1\right] e\left(\alpha_{L}, Q_{L}\right)}{\left(\frac{a_{H} p_{H}}{a_{L} p_{L}}-1\right)\left(1-p_{H}\right)(1-r)} .
$$

When (A39) holds, constraint ICA is not binding, therefore, $\lambda_{3}=0$.

The contradiction shows that $T_{H}=\frac{e\left(\alpha_{H}, Q_{L}\right)}{p_{L}}$ is not true. 
Therefore, $T_{H}>\frac{e\left(\alpha_{L}, Q_{L}\right)}{p_{L}}$ and $\lambda_{1}=0$. Substituting $\lambda_{1}=0$ into (A25) provides

$$
\lambda_{2}=\mu_{H}+\frac{p_{L}}{p_{H}-p_{L}}
$$

Substituting (A40) into (A28) provides

$$
\lambda_{3}=\frac{p_{L}\left(1-p_{H}\right)}{p_{H}-p_{L}} \frac{a_{H} p_{H}}{a_{L} p_{L}}
$$

And substituting (A40) and (A41) into (A26) and (A27) provides

$$
\lambda_{7}\left(p_{H}-p_{L}\right) a_{L} p_{L}=p_{H}\left(1-p_{L}\right) a_{L} p_{L}-p_{L}\left(1-p_{H}\right) a_{H} p_{H} .
$$

Since $\lambda_{7}>0$, (A42) implies

$$
\frac{a_{H}}{a_{L}}<\frac{1-p_{L}}{1-p_{H}}
$$

$\lambda_{3}>0$ implies

$$
T_{H}^{A}=\frac{(1-r) C}{a_{L} p_{L}}
$$

$\lambda_{2}>0$ implies

$$
T_{H}^{H}=\frac{\Delta e-\left(1-p_{H}\right)\left(\frac{a_{H} p_{H}}{a_{L} p_{L}}-1\right)(1-r) C}{p_{H}-p_{L}} .
$$

Jointly solving equation (A28) and (A30) provides

$$
\lambda_{r}=C\left(\frac{a_{L} p_{L}}{a_{H} p_{H}}-1\right) \lambda_{3}<0
$$

Therefore, $r=0$.

$T_{H}^{H}>\frac{e\left(\alpha_{L}, Q_{L}\right)}{p_{L}}$ requires 


$$
C<\frac{\Delta e-\left[\frac{p_{H}}{p_{L}}-1\right] e\left(\alpha_{L}, Q_{L}\right)}{\left(\frac{a_{H} p_{H}}{a_{L} p_{L}}-1\right)\left(1-p_{H}\right)(1-r)} .
$$

Case III: $\lambda_{3}>0, \lambda_{4}>0$ and $\lambda_{7}=0$;

Since $\lambda_{4}>0, T_{H}^{H}=0$. Therefore, $T_{H}^{A}>0$ and $\lambda_{5}=0$. Substituting $\lambda_{5}=0$ into (A28) and (A29) provides

$$
\lambda_{6}=\lambda_{3} \frac{\left[\left(1-a_{L} p_{L}\right) a_{H} p_{H}-\left(1-a_{H} p_{H}\right) a_{L} p_{L}\right]}{a_{H}}>0 .
$$

$\lambda_{6}>0$ implies $T_{L}^{A}=0$.

$\lambda_{3}>0$ implies

$$
T_{L}^{H}=a_{L} p_{L} T_{H}^{A}-(1-r) C .
$$

From (A28), we have

$$
\lambda_{2}=\frac{\mu_{H}\left(1-p_{H}\right) a_{H} p_{H}+\lambda_{3} a_{L} p_{L}}{\left(1-p_{H}\right) a_{H} p_{H}}>0,
$$

i.e., constraint ICH3 is binding. Therefore, we have

$$
T_{H}^{A}=\frac{\Delta e-\left(p_{L}-p_{H}\right)(1-r) C}{\left(1-p_{H}\right) a_{H} p_{H}-\left(1-p_{L}\right) a_{L} p_{L}} .
$$

Constraint IRL requires

$$
T_{H}^{A} \geq \frac{e\left(\alpha_{L}, Q_{L}\right)+\left(1-p_{L}\right)(1-r) C}{\left(1-p_{L}\right) a_{L} p_{L}} .
$$

Therefore, 


$$
C \leq \frac{\Delta e-\left[\frac{\left(1-p_{H}\right) a_{H} p_{H}}{\left(1-p_{L}\right) a_{L} p_{L}}-1\right] e\left(\alpha_{L}, Q_{L}\right)}{\left(\frac{a_{H} p_{H}}{a_{L} p_{L}}-1\right)\left(1-p_{H}\right)(1-r)} .
$$

When (A53) holds, $\lambda_{1}=0$. Substituting $\lambda_{1}=0$ into (A25) and (A26). From (A25),

(A26), (A27) and (A28), we have

$$
\begin{aligned}
& \lambda_{4}=\frac{\left(1-p_{H}\right) a_{H} p_{H} p_{L}-\left(1-p_{L}\right) a_{L} p_{L} p_{H}}{\left(1-p_{H}\right) a_{H} p_{H}-\left(1-p_{L}\right) a_{L} p_{L}} \text { and } \\
& \lambda_{3}=\frac{\left(1-p_{H}\right) a_{H} p_{H}\left(1-p_{L}\right)}{\left(1-p_{H}\right) a_{H} p_{H}-\left(1-p_{L}\right) a_{L} p_{L}} .
\end{aligned}
$$

$\lambda_{3}>0$ and $\lambda_{4}>0$ require

$$
\frac{a_{H}}{a_{L}} \geq \frac{1-p_{L}}{1-p_{H}} .
$$

It can be shown that $\lambda_{r}=\lambda_{3}\left(\frac{a_{L} p_{L}}{a_{H} p_{H}}-1\right) C<0$. Therefore, $r=0$.

\section{Proof of Proposition 5.}

Properties (i) and (ii) have been shown in the analysis of Case III. The proofs of Properties (iii) - (v) are as follows.

In Case III, the employer's expense is

$$
E X=\left(1-p_{L}\right) a_{L} p_{L}\left\{\frac{\Delta e-\left(p_{L}-p_{H}\right)(1-r) C}{\left(1-p_{H}\right) a_{H} p_{H}-\left(1-p_{L}\right) a_{L} p_{L}}\right\}+\mu_{H}\left(1-p_{H}\right) C++\mu_{H} \Delta e .
$$

Since the employer's expense without the appeals process is 
$\left(\mu_{H}+\frac{1}{\frac{p_{H}}{p_{L}}-1}\right) \Delta e$, the appeals process is valuable if and only if $E X<\left(\mu_{H}+\frac{1}{\frac{p_{H}}{p_{L}}-1}\right) \Delta e$.

It can be shown that the appeals process is always valuable and the principal's welfare is increasing in $C$ when $r=0$ and the opposite is true when $r=1$ and $C$ is sufficiently large.

It can be readily shown that $\frac{d E X}{d \frac{a_{H}}{a_{L}}}<0$.

Further, from the analysis for the costless appeals process, by continuity, $E X$ can increase in $p_{H}$ for sufficiently small $C$. 


\section{References}

Aram, J.D., \& Salipante, P.E., Jr. 1981. An Evaluation of Organizational Due Process in the Resoluation of Employee/Employer Conflict. Academy of Management Review 6, 197-204

Baiman, S. \& Demski, J. 1980. Economically Optimal Performance Evaluation and Control System. Journal of Accounting Research 18, 184-220

Bebchuk, L.A. 1984. Litigation and Settlement under Imperfect Information. Rand Journal of Economics 15, 404-415.

Caillaud, B., Guesnerie, R. and Rey., P. 1992. Noisy Observation in Adverse Selection Models. Review of Economic Studies 59, 595-615

Cremer, J. 1995. Arm's Length Relationships. Quarterly Journal of Economics 110, 275295

Dai, C. 2004. The Appeals Process in Incentive Problems. Working paper, Department of Economics, University of Florida

Daughety, A.F. and Reinganum, J.F. 2000. Appealing Judgments. Rand Journal of Economics 31, 502-525.

Demougin, D.M. and Garvie, D. A. 1991. Contractual Design with Correlated Information under Limited Liability. Rand Journal of Economics 22, 477-489.

Dickens, W. T., Katz, L.F., Lang, K. and Summers, L.H. 1989. Employee Crime and the Monitoring Puzzle. Journal of Labor Economics 7, 331-347.

Dye, R.A. 1986. Optimal Monitoring Policies in Agencies, Rand Journal of Economics 17, 339-350.

Folger, R. 1987. Distributive and Procedural Justice in the Workplace. Social Justice Research 1, 143-159

Greenberg, J. 1986. Determinants of Perceived Fariness of Performance Evaluations. Journal of Applied Psychology 71, 340-342

Greenberg, J. 1990. Organizational Justice: Yesterday, Today, and Tomorrow. Journal of Management 16, 399-432.

Khalil, F. 1997. Auditing without Commitment. Rand Journal of Economics 28, 629-640

Lewis, T. and Poitevin, M. 1997. Disclosure of Information in Regulatory Proceedings. Journal of Law, Economics, \& Organization 13, 50-73. 
Mookherjee, D. and Png, I.P.L. 1992. Monitoring vis-à-vis Investigation in Enforcement of Law. American Economic Review 82, 556-565.

Okun, A.M. 1975. Equality and Efficiency: The Big Tradeoff. Washington, DC: The Brooking Institution.

Paese, P.W., Lind, E.A. \& Kanfer, R. 1988. Procedural Fairness and Work Group Responses to Performance Evaluation Systems. Social Justice Research 2, 193-205

Picard, P. 1987. On The Design of Incentive Schemes under Moral Hazard and Adverse Selection. Journal of Public Economics 33, 305-331.

Polinsky, M. and Shavell, S. 2000. “The Fairness of Sanctions: Some Implication for Optimal Enforcement Policy.” American Law and Economic Review 2, 223-237

Reinganum, J.F., and Wilde L.L. 1986. Settlement, Litigation, and the Allocation of Litigation Costs. Rand Journal of Economics 17, 557-566.

Riordan, M.H. and Sappington, D.E.M. 1988. Optimal Contracts with Public Ex-post Information. Journal of Economic Theory 45, 189-199.

Rubinfeld, D.L., and Sappington, D.E.M. 1987. Efficient Awards and Standards of Proof in Judicial Proceedings. Rand Journal of Economics 18, 308-315.

Sappington, D.E.M., 1986. Commitment to Regulatory Bureaucracy. Information Economics and Policy 2, 243-258.

Shavell, S. 1995. The Appeals Process As A Means of Error Correction. Journal of Legal Studies 24, 379-426.

Shavell, S. 1982. The Social versus Private Incentive to Bring Suit in a Costly Legal System. Journal of Legal Studies 11, 334-340.

Sheppard, B.H., Lewicki, R.J., \& Minton, J.W. 1992. Organizational Justice: The Search for Fairness in the Workplace. New York: Lexington Books

Sheppard, B.H. 1985. Justice Is No Simple Matter: Case for Elaborating Our Model of Procedural Fairness. Journal of Personality and Social Psychology 49, 953-962.

Spitzer, M. and Talley, E. 2000. Judicial Auditing. Journal of Legal Studies 29, 649-

Townsend, R.M. 1979. Optimal Contracts and Competitive Markets with Costly State Verification. Journal of Economic Theory 21, 265-293 